\title{
Procedural Fairness, Budget Performance and Managerial Performance: A View from Contingency Approach
}

\section{${ }^{1}$ Mohd Nor Yahaya, ${ }^{1}$ Jegak Anak Uli and ${ }^{1}$ Norlaila Mazura Hj. Mohaiyadin}

${ }^{1}$ Faculty of Defence Studies \& Management, National Defence University of Malaysia, Sungai Besi Camp, 57000 Kuala Lumpur, Malaysia

Correspondence Author: Mohd Nor Yahaya, Faculty of Defence Studies and Management, National Defence University of Malaysia, Sungai Besi Camp, 57000 Kuala Lumpur,

Tel: +6012-2064012; E-mail: mohdnor@upnm.edu.my

Received date: 12 January 2018, Accepted date: 10 March 2018, Online date: 20 March 2018

Copyright: (c) 2018 Mohd Nor Yahaya et al. This is an open-access article distributed under the terms of the Creative Commons Attribution License, which permits unrestricted use, distribution, and reproduction in any medium, provided the original author and source are credited.

\begin{abstract}
This study examines the effect of procedural fairness on managerial performance in budget setting. Using contingency approach, it was proposed that procedural fairness affect managerial performance via mediating variables of budget performance. The result of path analysis of 128 budget managers is supported, thus suggesting that budget performance acted as contingent variables that mediate the relationship between procedural fairness and managerial performance. The study concludes that organization have to ensure managers with budget responsibility should have higher budget performance which lead to improved overall managerial performance.
\end{abstract}

Key words: Fairness; Budget; Management; Contingency

\section{INTRODUCTION}

It is viewed that the relationship between procedural fairness and budget performance is important in budget process because of their roles which are antecedent to managerial performance. However, not much evidence was obtained for literature on the relationship between these three variables for the studies were limited. Thus, further study is needed to add to the literature regarding the roles by these three variables. Therefore, the objective of this study to examine the relationship between procedural fairness, budget performance and managerial performance. The inclusion of the variables in the present study is considered timely and appropriate.

One of the earlier studies related to fairness and budget performance is provided by Maiga [1]. In his study, Maiga found budgetary fairness as one of the key factors linking to budget satisfaction as an intervening variables and finally budget performance. The author found positive relationship between the three fairness dimensions and budget performance. The study showed the full dimensions of fairness that are procedural fairness, distributive fairness and interactional fairness were significantly correlated with budget satisfaction and budget performance.

This paper highlights fairness dimension of procedural fairness as antecedent to budget performance and managerial performance. Exploring contingency setting, this paper relates cause and effect relationship between procedural fairness, budget performance and managerial performance on the ground that their action is contingent to another. Procedural fairness acted as a causal antecedent to affect budget performance and consequently affect managerial performance. Hence, the study proposed that budget performance mediates the relationship between procedural fairness on managerial performance. This is consistent with the contingency approach which view that 'the effect of one variable on another depends upon some third variable' [2]. Sometimes referred to as 'situation-dependent theory' [3], it is based on the notion that the nature of the relationship depends on situational features that may vary from one situation to another. The relationship is clearly depicted in the research conceptual framework in Figure 1 below:

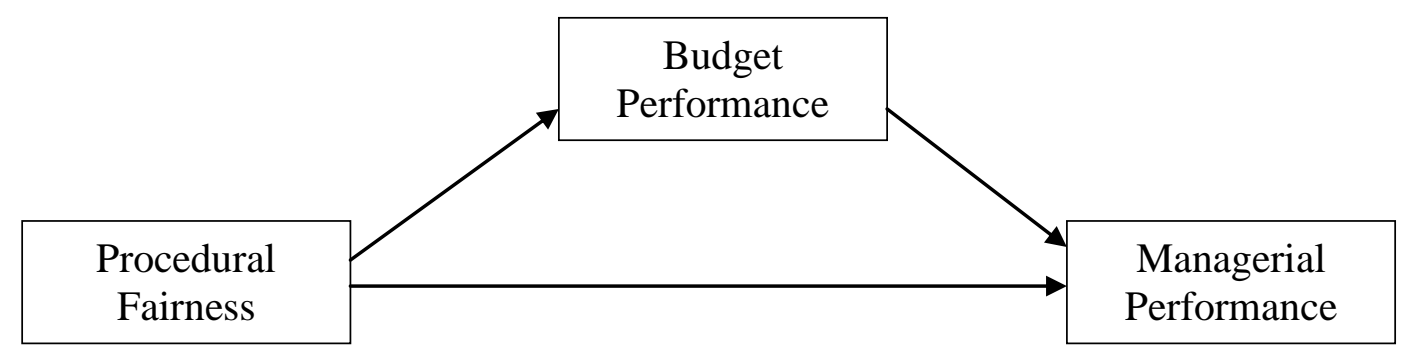

Fig. 1: Research conceptual framework showing relationship between procedural fairness, budget performance and managerial performance 
Procedural Fairness and Managerial Performance:

Early empirical study on procedural fairness and performance relationship found inconsistent results. Earley \& Lind [4] as noted in Lau \& Lim [5] found positive relationship between procedural justice and performance. Similarly, Tang \& Sarfield-Baldwin [6] suggested that fair and consistent rules will lead to positive perception of procedural justice, which in turn will lead to positive managerial outcome. Positive relationship was also identified by Wentzel [7] who suggested that performance is increases under high condition of justice. Wentzel [7] also noted that perceptions of fairness can improve performance by increasing the manager's commitment on budgetary goals. Also, Rachman [8] found significant effect of procedural fairness on performance which meant improvement on the procedural fairness. The results showed that $\mathrm{t}$-statistic value of 2.06 was greater than critical values of 1.645 at significant level of $5 \%$ (P value $<0.05$ ). However, Yucel \& Gunluk [9] found negative relation between procedural fairness and performance, therefore this study attempts to test this relationship in the public-sector organizations. The relationship is illustrated in Figure 2 below. The hypothesis to be tested is:

H1: Procedural fairness has a positive and significant direct effect on managerial performance

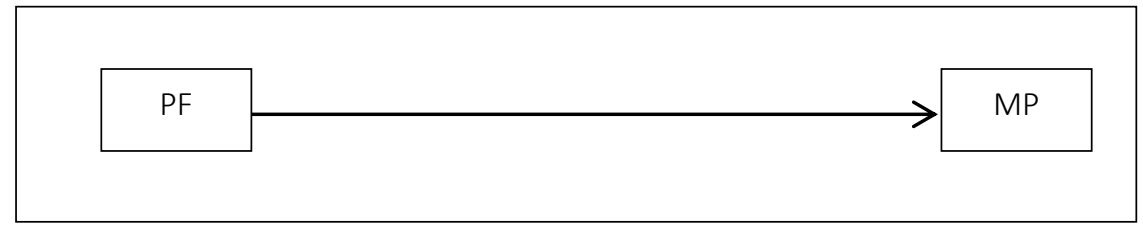

Fig. 2: Path relationship between procedural fairness and managerial performance

Procedural Fairness and Budget Performance:

Procedural fairness will affect employees' performance when the employees are given an opportunity to participate in the decision making [10]. Perceived procedural fairness may influence the budget performance when the subordinates believe that they are given a fair treatment over the budgeting process and outcomes' decisions [11]. When the employees feel they have been receiving fair treatment by their superior during the budget setting process, it will drive the subordinates to improve on the budget performance. According to Wentzel [7], fairness can improve performance by increasing the manager's budgetary goals. The relationship is illustrated in Figure 3 below. Thus the following hypothesis is developed and put forward:

H2: Procedural fairness has a positive and significant direct effect on budget performance.

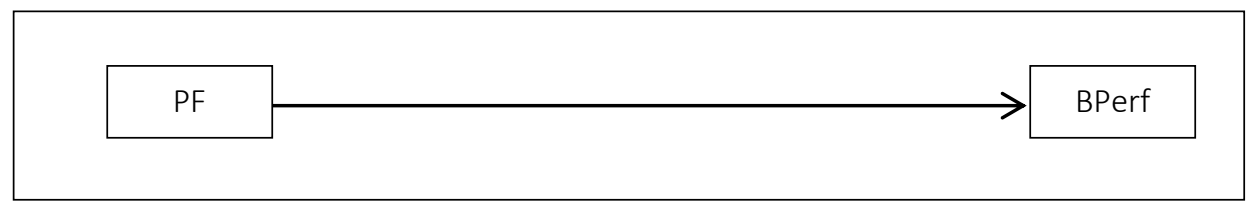

Fig. 3: Path relationship between procedural fairness and budget performance

Budget Performance and Managerial Performance:

Budget performance is related to managerial performance when the manager believes that the outcome of the budget allocation fulfils their budget requirement and meets their budgetary target. In view of the characteristic of path goal theory, it is noted that higher budget performance indicates lesser barrier to goal accomplishments due to the increase in confidence to achieve work outcomes. The relationship is illustrated in Figure 4 below. Based on the explanation, the following hypothesis is developed:

H3: Budget performance has a positive and significant direct effect on managerial performance.

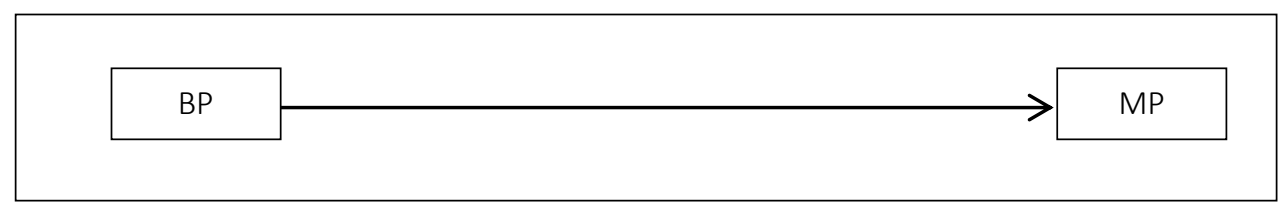

Fig. 4: Path relationship between budget performance and managerial performance

Procedural Fairness, Budget Performance and Managerial Performance:

Procedural fairness affects employee performance when the employees are given opportunity to participate in decision making [10]. Perceived procedural fairness may influence budget performance when the subordinates believe they are given a fair treatment over the budgeting process and outcomes decisions [11]. When the employee feels they have been receiving fair treatment by their superiors during the budget setting process, it will drive the subordinates to improve budget performance. According to Wentzel [7], fairness can improve performance by increasing the manager's budgetary goals. It is suggested that improved in budget performance improves managerial performance. The relationship is illustrated in the Figure 5 below. Thus, the following hypothesis is developed and put forward: 


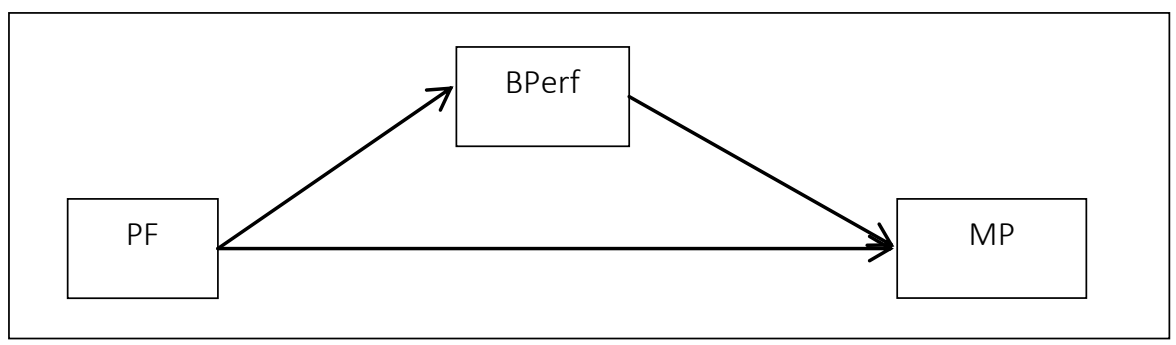

Fig. 5: Path relationship between procedural fairness, budget performance and managerial performance

\section{Research Methodology:}

A data gathered from total of 128 budget managers in a Malaysian public organization were analysed using PLS SEM. PLS SEM was used because it is able to deal with small sample size for data analysis and normal data distribution is not necessary, easy to be illustrated using path analysis diagram [12]. A mediating effect exists when a third variable intervenes between two other related constructs [12]. The mediation effect is reflected in the relationship when it causes the continuous significant effect to the criterion variable. The degree of mediation effect of organizational commitment is measured using Variance Accounted For (VAF) as suggested by Hair et al., [12] approach.

The instruments that were used to measure procedural fairness were adapted from earlier research as cited in Maiga [1] works. Organizational commitment and managerial performance were adapted and modified from earlier studies as cited in Yahaya et al. [9], Zainuddin \& Isa [13]. For this paper, all the items in research instruments were using five points Likert - scale ranging from (1) strongly disagree) to (5) strongly agree. All the instruments used were replicated and modified from earlier research and has established very high validity and internal consistency reliability. Cronbach Alpha were observed above 0.8 , surpassing the recommended range of 0.7 [14]. Composite reliability for all the items were above 0.6 as recommended by Hair et al., [12]. Average Variance Extracted (AVE) to evaluate convergent validity shows the AVE of 0.5 and above [12]. These validity and reliability results indicate that items used in the study are fit for measurement model for PLS SEM analysis using Smart PLS.

\section{RESULTS AND DISCUSSION}

Procedural Fairness and Managerial Performance:

Hypothesis testing of $\mathrm{H} 1$ which proposed procedural fairness has a positive and significant effect on managerial performance provides the result as shown in Figure 6. It shows a positive and significant effect of procedural fairness on managerial performance $(\beta=0.618, t>11.058, p<0.000)$. $R$ square indicates procedural fairness explain $38 \%$ of managerial performance. Thus, the result is consistent with earlier studies by Libby [15], Early \& Lind [4] as noted in Yucel \& Gunluk [9], Lau \& Lim [5], and Rachman [8] which found positive relationship between procedural justice and managerial performance, the hypothesis is accepted.

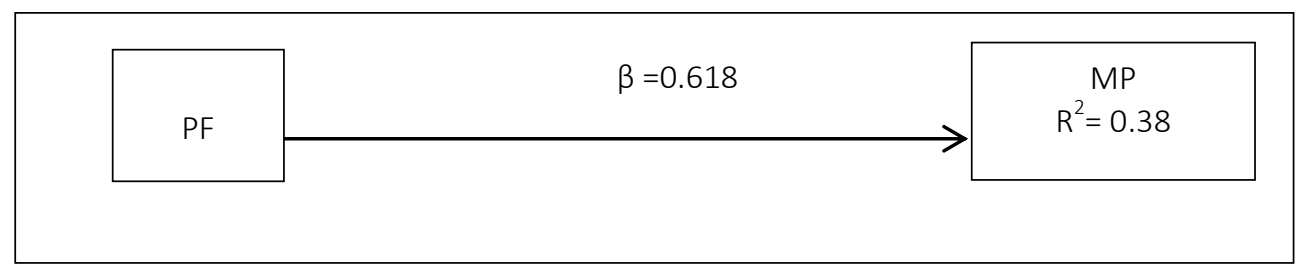

Fig. 6: Path relationship between procedural fairness and managerial performance

The result of the direct effect between procedural fairness on managerial performance is expected as the procedural variables play an important role in any organization across managerial functions. In the context of budget setting, managers have the opportunity to voice their budget's requirement. Without a proper, right and just procedure, a manager's job function may not be carried out properly as they may find difficulties in managing the resources effectively. Therefore, it is important to highlight that the organizational activities related to budgeting procedures should satisfy organizational members as this may affect in improved managerial performance. As Maiga \& Jacobs [10] noted, procedural fairness recognizes positive benefits of allowing employees to participate in decision making, thus affected to improve performance.

\section{Procedural Fairness and Budget Performance:}

Hypothesis testing of $\mathrm{H} 2$ which proposed procedural fairness has a positive and significant effect on budget performance provides the result as shown in Figure 7. It shows a positive and significant effect of procedural fairness on budget performance $(\beta=0.491, t>7.020, p<0.000)$. The $R$ square indicates procedural fairness explain $24 \%$ of budget performance. Thus, the hypothesis is accepted.

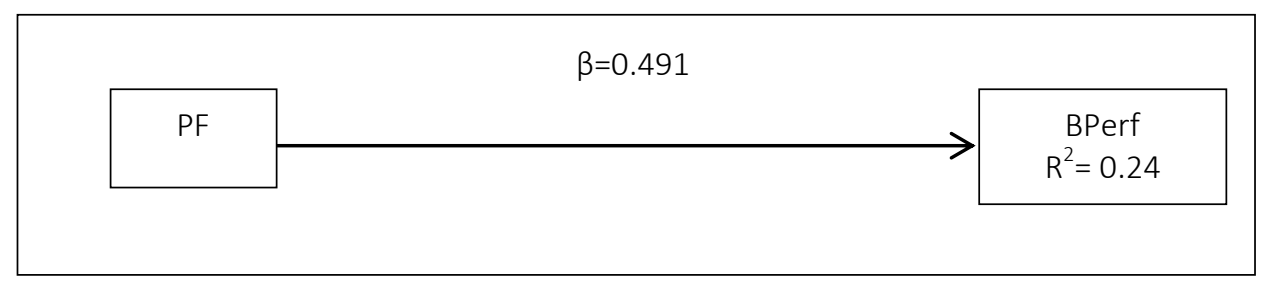

Fig. 7: Path relationship between procedural fairness and budget performance

The result of the direct effect between procedural fairness on budget performance is as expected on the view that fair budget procedure enhances budget performance as the managers believe that the process of budget allocation has met their expectation, it is not affected by bias and it systematically follows the applicable rules and guidelines which are common to the entire organization. Higher budget performance, on the other hand will indirectly improve the managers' performance at the highest level and ensures organizational goals are achieved. 
Hypothesis testing of $\mathrm{H} 3$ which proposed budget performance has a positive and significant effect on managerial performance provides the result as shown in Figure 8. It shows a positive and significant effect of budget performance on managerial performance $(\beta=0.598, t>9.527$, $p<0.000)$. The $R$ square indicates budget performance explains $36 \%$ of managerial performance. Thus, the hypothesis is accepted.

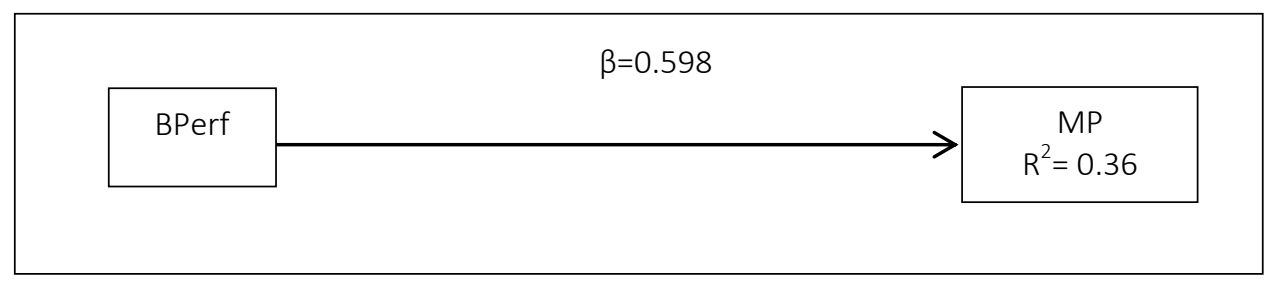

Fig. 8: Path relationship between budget performance and managerial performance

As expected, budget performance and managerial performance are positively related. It is identified that in the budget process, higher budget performance means the managers are satisfied and accept what has been decided and determined by their superior. Their willingness to accept the portion of budget allocation, indicate that they agreed to execute the departmental activities without much concern on the limitation, considering that the available resources is adequate for the running of the departmental activities. The willingness to execute will lead to more effort and initiative to ensure the budgetary goals are achieved and meet their objective. This in turn will lead to improve managerial outcome in term of performance.

Procedural Fairness, Budget Performance and Managerial Performance:

Hypothesis testing of $\mathrm{H} 4$ which proposed budget performance mediates the effect of procedural fairness on managerial performance provides the result in Figure 9. The bootstrapping in PLS SEM procedure shows the combination of procedural fairness and budget performance has explained $49 \%$ variance in managerial performance. Procedural fairness and managerial performance show positive and significant effect $((\beta=0.425, t>6.209, p<0.000)$ while procedural fairness has positive and significant effect on budget performance with $\mathrm{R}^{2}$ at $0.24(\beta=0.489, \mathrm{t}>6.737, \mathrm{p}<0.000)$. The effect of budget performance on managerial performance is significant $(\beta=0.385, \mathrm{t}>5.194, \mathrm{p}<0.000)$. Following Hair et al., [12], method of assessing VAF value to determine the strength of mediator effect, the model shows VAF of 0.31 . Consequently, this value indicates that $31 \%$ of procedural fairness effect on managerial performance is explained via budget performance mediator. Since the value of VAF is larger than $20 \%$ but smaller than $80 \%$, it is concluded that partial mediator exists. The result conforms to Hair et al. [12] which suggest that the mediating effect only exist when indirect effect between third variable and criterion variable is significant. The result provides evidence that budget performance does partially mediates the relationship between procedural fairness and managerial performance. Therefore, the hypothesis is supported.

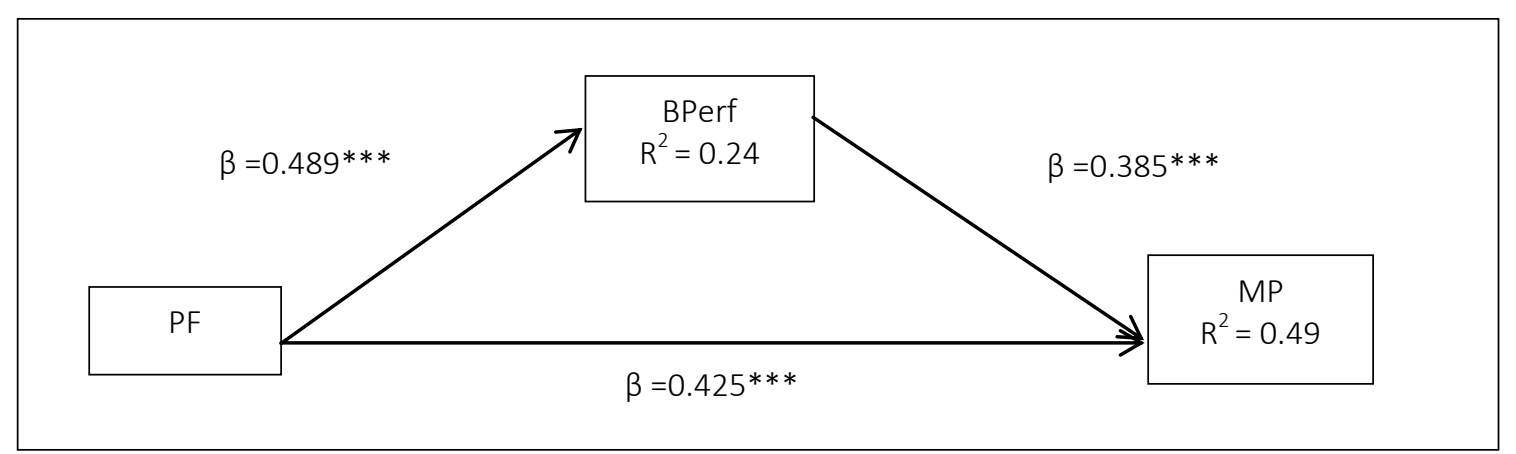

Note: Significant at $* \mathrm{t}>1.96(\mathrm{p}<0.05)$

Fig. 9: Path relationship between procedural fairness, budget performance and managerial performance

As expected, budget performance plays mediating effect on the relationship between fairness and performance. As supported in earlier direct effect studies, both procedural fairness has a direct positive and significant effect on both budget performance and managerial performance, indicating the presence of budget performance as mediator has an influence on managerial performance. This means that budget performance acts as a contingent factor to affect performance, consistent with contingency setting theory. Due to limited studies involving budget performance in fairness and managerial performance relationship, this study offers new evidence to the literature, with regards to budget setting in public sector. Therefore, it is concluded that fairness in budget setting influenced the budget performance on the allocation of resources and thus lead to positive managerial outcomes, that is performance.

The results support the significant mediating roles of budget performance in the relationship between procedural fairness and managerial performance. Management should ensure their budget managers achieve higher performance as higher budget performance lead to improved managerial performance. Within contingency setting, it is clearly evidence that budget performance acted as a contingent factor that influence managerial performance.

\section{Conclusion:}

This paper examines the relationship between procedural fairness, budget performance and managerial performance in budget setting using a sample of 128 budget managers from a Malaysian public-sector organization. It was hypothesized that the relationship between procedural fairness with managerial performance is mediated by budget performance. The findings suggest that fairness is an important variable that affect budget performance and finally lead to improvement in managerial performance. The paper highlights new evidence on theory development pertaining to the application of justice theory within contingency setting. It is important to express that justice model in workplace is not an isolation factor that affect managerial attitude and behaviour, but it should be seen broadly in other context such as contingency environment.

It is also viewed that justice is seen to be working in mechanistic environment budget setting without any interference from mechanistic rules. Thus suggesting that mechanistic condition appears not having an influence on justice in workplace. Consequently, this condition suggests the role of justice is communal in any organizational setting.

The implication of this paper indicates that the design of budgetary framework within the organization should inclusively take into account managers behaviour and outcomes. In particular, it is important for the management to emphasis fairness and budget outcome in their budget setting to ensure managers' willingness to perform significantly at higher productivity. Ultimately, this would contribute towards high organizational success. The result of this study was based on a single mechanistic public organization. Therefore, it cannot be generalized to other context. Additionally, this study views only a single causation effect of fairness on performance. Therefore, future studies on fairness may incorporate other variables that could influence managers' performance such as budget satisfaction and leadership styles. 
[1] Maiga, S., 2006. Fairness, budget satisfaction and budget performance: A path analytic model of their relationships, Advance in Accounting Behavioral Research, 9: 87-111.

[2] Donaldson, L., 2001. The contingency theory of organizations. Thousand Oaks, CA Sage.

[3] Charpentier, C., 1998. Budgetary participation in a Public Service Organization. Working Paper Series in Business Administration, 3: 1-25.

[4] Earley, P.C. and E.A. Lind, 1987. Procedural justice and participation in task selection: The role of control in mediating justice judgements. Journal of Personality and Social Psychology, 52: 1148-1160.

[5] Lau, C.M. and S. Lim, 2002. The intervening effect of participation on the relationship between procedural justice and managerial performance. British Accounting Review, 34: 55-78.

[6] Tang, T.L.P. and L.J. Sarsfield-Baldwin, 1996. Distributive and procedural justice as related to satisfaction and commitment. S. A. M. Advanced Management Journal, 61(3): 25-31.

[7] Wentzel, K., 2002. The influence of fairness perceptions and goal commitment on managers' performance in a budget setting. Behavioural Research in Accounting, 14: 247-271.

[8] Rachman, S., 2014. The effect of organization commitment and procedural fairness on participative budgeting and its implication to performance moderating b management accounting information. Review of Integrative Business and Economics Research, 3(1): 201-218.

[9] Yucel, R. and M. Gunluk, 2007. Effects of Budgetary control and justice perceptions on the relationship between budgetary participation and performance. Journal of Global Strategic Management, 1(2): 82-94.

[10] Maiga, A.S. and F.A. Jacobs, 2007. Budget participation's influence on budget slack: the role of fairness perceptions, trust and goal commitment. Journal of Applied Management Accounting Research, 5(1): 39-58.

[11] Thibaut, J. and L. Walker, 1975. Procedural justice: a psychological analysis. Hillsdale, N. J.: Lawrence Erlbaum Associates, vii.

[12] Hair, J.F., G.T.M. Hult, C.M. Ringle and M. Sarstedt, 2014. A primer in partial least squares structural equation modelling (PLS-SEM). Thousand Oaks, CA Sage.

[13] Zainuddin, S. and S. Isa, 2011. The role of organizational fairness and motivation in the relationship between budget participation and managerial performance: A conceptual paper. Australian Journal of Basic and Applied Sciences, 5(12): 641-648.

[14] Pallant, B., 2013. SPSS survival manual $5^{\text {th }}$ edition, Mc Graw Hill, London.

[15] Libby, T., 1999. The influence of voice and explanation on performance in a participative budgeting setting. Accounting Organization and Society, 24(2): 125-137. 